\title{
La Antropología desde el Derecho: Derecho consuetudinario Gallego y Etnografía
}

\author{
The Antrophology Through the Law: \\ Galician costumary law and Ethnography
}

\author{
Ramón P. RODRÍGUEZ MONTERO \\ Universidade da Coruña \\ ramonp@udc.es \\ José Luis RAMOS BLANCO \\ Universidade da Coruña \\ ramosblanco.j1@gmail.com
}

Recibido: 24 de noviembre de 2014

Aceptado: 14 de abril de 2015

\section{Resumen}

Estudio mediante el que se pretenden poner de manifiesto las necesarias interrelaciones que se producen entre la ciencia etnográfica y la jurídica, especialmente a los efectos de la posible determinación, conocimiento y estudio, tanto histórico como actual, de las diversas peculiaridades jurídicas de carácter consuetudinario existentes en el específico caso del ordenamiento jurídico civil gallego.

Palabras clave: costumbre jurídica; ordenamiento jurídico civil gallego; peculiaridades jurídicas consuetudinarias; etnografía; ciencia jurídica.

\begin{abstract}
With this essay we try to unveil some necessary interrelations between ethnographic enquiries and legal studies. They are especially relevant to disclose the customary features of the present Galician civil law. This is done taking into account the meaning of ethnographic results and historical analysis for legal scholars.
\end{abstract}

Keywords: customary law; galician civil law; legal ethnography; legal science.

Referencia normalizada: Rodríguez Montero, R.P. y Ramos Blanco, J.L. (2015) La Antropología desde el Derecho: Derecho Consuetudinario Gallego y Etnografía, en Revista de Antropología Social 24, 189-199.

SUMARIO: 1. Dudas y oscuridades en la denominada "experiencia jurídica gallega". El posible contenido del Derecho consuetudinario gallego. 2. La intervención doctrinal en la determinación, configuración y desarrollo de las peculiaridades jurídico-civiles gallegas. Problemática básica y algunas paradojas. 3. El importante papel otorgado a la costumbre en la LDCG de 1995. Los usos y costumbres notorios. La posible determinación jurisprudencial de la costumbre. 4. La posición de la costumbre en la vigente LDCG de 2006 y en 
el ordenamiento jurídico-civil de Galicia. El necesario recurso por parte de los juristas a los antropólogos como conclusión. 5. Referencias bibliográficas.

\section{Dudas y oscuridades en la denominada "experiencia jurídica gallega". El posible contenido del Derecho consuetudinario gallego}

Nuestra aproximación y contacto desde el ámbito del Derecho con la Antropología social, y dentro de ésta, especialmente, la jurídica, se justifica por la que consideramos como una evidente necesidad intelectual dirigida a lograr, al realizar diversas y puntuales investigaciones en el ámbito jurídico-civil gallego, el mayor rigor científico posible en sus resultados y conclusiones.

De un tiempo a esta parte nos venimos ocupando, entre otros, del estudio de la que, en terminología particular y propia, hemos denominado "experiencia jurídica gallega", cuyo posible interés e importancia para la Ciencia jurídica en general y para los juristas en particular, tanto en el aspecto didáctico como en el científico, ya tuvimos ocasión de resaltar en otros escritos anteriores (Rodríguez Montero, 2012: 25 y ss.).

La "experiencia jurídica gallega", identificable en cuanto a su contenido con el proceso histórico seguido desde la formación hasta la consolidación legislativa de las peculiaridades jurídicas propias de Galicia, las características de las mismas, y su posterior desarrollo operado doctrinal, jurisprudencial y legislativamente hasta nuestros días, ofrece, a nuestro entender, diversas cuestiones que cabe calificar como de particular interés. Entre las mismas, sucintamente y por lo que se refiere al señalado proceso de formación, cabe indicar que el mismo todavía presenta algunas dudas y oscuridades en cuanto a cuestiones tan importantes como, por ejemplo y entre otras, la determinación de las posibles motivaciones de fondo que condujeron a la consideración de Galicia como territorio de Derecho foral, o las posibles influencias en el ámbito jurídico-civil gallego del sistema de Derecho civil común, representado por el Código civil; por lo que a su contenido atañe, su determinación ha presentado notables problemas e incertidumbres, habiendo sufrido el mismo algunas deformaciones, precisamente a consecuencia de su carácter consuetudinario, motivando dificultades notables para llevar a cabo su estudio; $\mathrm{y}$, por último, respecto al análisis de su desarrollo, resulta oportuno resaltar que éste presenta un atractivo especial por haberse realizado en puntuales y diversos momentos históricos, fundamentalmente, por vía doctrinal y jurisprudencial.

\section{La intervención doctrinal en la determinación, configuración y desarrollo de las peculiaridades jurídico-civiles gallegas. Problemática básica y algunas paradojas}

Centrando nuestra atención en la determinación del posible contenido del en tiempos pasados denominado Derecho civil especial gallego, cabe indicar que, tradicionalmente, se ha venido sosteniendo como característica distintiva del mismo, hasta tiempos más bien recientes, como se acaba de decir, su carácter consuetudinario. 
Históricamente la costumbre se ha presentado como la genuina fuente originaria del Derecho civil de Galicia, circunstancia ésta que encuentra su justificación a partir de la toma en consideración de toda una serie de factores de tipo económico, social y político, que, al hilo del proceso histórico desenvuelto en la formación de la nacionalidad española, se dieron en la Comunidad gallega y que condicionaron su propia experiencia jurídica (Rodríguez Montero, 2005: 188 y ss.).

El hecho de que históricamente el Derecho gallego tuviese el carácter de consuetudinario, concretándose, según se decía, en una serie de prácticas y costumbres gallegas tradicionales que se desarrollaban al margen de la legislación real castellana, apartadamente del Derecho real común en que se convirtió el Derecho castellano, planteaba inmediatamente otra nueva cuestión importante: ¿cuáles eran realmente las instituciones consuetudinarias peculiares, propias, autóctonas y privativas, representativas de Galicia, que merecían la consideración de forales y que conformaban el en su momento denominado Derecho foral gallego - más que Derecho gallego, por quedar reducido el mismo, a tenor del R.D. del Ministerio de Gracia y Justicia de 2 de febrero de 1880, a dichas instituciones consuetudinarias y tradicionalesque, según se decía, merecían ser conservadas?

La respuesta a la pregunta formulada obtuvo unos resultados distintos y, a su vez, sucesivamente más amplios en cuanto al número de posibles instituciones existentes, tras realizar una lectura atenta y ordenada de una serie de documentos, aparecidos sucesivamente en el tiempo desde que se inició la etapa codificadora - durante y después de la misma, en momentos cronológicos diferentes, hasta llegar a la Compilación de Derecho Civil Especial de Galicia de 1963-; unos documentos en los que se realizaban diferentes y diversas referencias doctrinales a las "peculiaridades jurídicas" o "instituciones" que supuestamente integrarían el denominado "Derecho civil propio y singular" de Galicia, o "Derecho especial gallego". Dicha lectura puede producir una sensación de confusión o perplejidad al estudioso o investigador del Derecho -poniendo de manifiesto las incertezas y dudas, unas cumplidamente señaladas y otras no, en algunos casos más o menos razonables, que, en nuestra opinión, todavía no han sido resueltas en su totalidad y de una forma definitiva, sino, tan sólo, parcialmente-(Rodríguez Montero, 2012: 32 nota.13; 65 y ss.).

La intervención de la doctrina en el proceso de configuración y determinación de las instituciones y peculiaridades jurídicas contenidas en las normas fundamentales del Derecho civil de Galicia no se llevó a cabo de una manera unívoca, sino, más bien, con discrepancias y diferencias - en algunos casos sustanciales e irreconciliables- que, en diversos aspectos, se proyectaron en el tiempo.

Volvía a plantearse, por tanto y a tenor de ello, la pregunta trascendental a la que, en nuestra opinión, quizá todavía sólo se ha contestado en parte, de manera parcial, superficial y sincrónicamente: ¿cuáles fueron realmente las instituciones peculiares, propias, autóctonas y privativas, representativas de Galicia, que merecieron la consideración de forales y que, por consiguiente, integraron el denominado Derecho (consuetudinario) gallego?

Para contestar a esta pregunta consideramos que resultaba imprescindible realizar un estudio de dichas "peculiaridades jurídicas" o "instituciones" —que 
realmente hubiesen integrado el anteriormente denominado Derecho civil especial gallego-, llevado a cabo más de forma diacrónica que sincrónica — a consecuencia del aludido proceso de progresiva ampliación doctrinal a que hemos hecho referencia-, y dirigido tanto a la concreta determinación de dichas instituciones en los sucesivos momentos históricos, así como también a la constatación o confirmación de la efectiva vigencia en el tiempo de las mismas y de su correcta regulación.

Cabría, por consiguiente, formularse otra pregunta sucesiva a la anterior: las que habitualmente se vienen planteando como "peculiaridades jurídicas" o "instituciones" jurídicas gallegas tradicionales, cuya existencia había sido efectivamente constatada, ¿fueron reguladas correctamente, tal y como surgieron, o sufrieron algún tipo de modificación o alteración al realizar esa regulación de las mismas?

La formulación de las preguntas indicadas encontraría su explicación en la circunstancia de que, a nuestro juicio, se suele aludir a algunas "peculiaridades jurídicas" que, o nunca han existido como tales, o bien que, habiendo existido de forma efectiva, su regulación en la Ley de Derecho Civil de Galicia (LDCG) — de 1995, y posterior de 2006 - resultaría extraña a la configuración original de tales figuras, con cuya realidad quizá no se correspondan.

Dos ejemplos especialmente significativos de lo señalado podrían encontrarse - siempre según nuestro propio criterio - , respectivamente, por una parte, en el reconocimiento realizado por el legislador gallego, en la LDCG, de la usucapión como posible forma de constitución de las servidumbres de paso; y por otra, en la manera como se ha regulado la serventía, que también apareció recogida en la referida Ley gallega.

Como hemos tratado demostrar en otros escritos (Rodríguez Montero, 2001: 133 y ss.), en nuestra opinión, la introducción y regulación por el legislador gallego —en el art. 25 de la LDCG de 1995; y en los arts. 82.1 y 88.1 de la LDCG de 2006- de la usucapión extraordinaria como posible forma de adquisición de las servidumbres de paso, se realizó de una forma totalmente novedosa y desconectada de la tradicional realidad consuetudinaria gallega, tergiversándola. Respondiendo, según se decía, a una supuesta necesidad social, sentida desde antiguo en el ámbito agrario gallego, la adquisición por usucapión de las servidumbres de paso, se presentó como una de las costumbres más respetadas dentro del ámbito gallego, lo cual, como ha sido puesto de manifiesto, tanto doctrinal como jurisprudencialmente, en absoluto se correspondía con la realidad (Rodríguez Montero, 2001: 156 y ss.).

La regulación hasta entonces aplicable en materia de adquisición de servidumbres de paso en Galicia, con anterioridad a las dos leyes autonómicas citadas, era la establecida en el sistema del ordenamiento jurídico-civil común (Código civil), solventándose la falta de reconocimiento espontáneo de los servicios de paso necesarios para la realización de tareas agrícolas en las fincas a través del recurso al art. 564 del Código civil, o, en su caso, mediante la constatación testifical de no existir memoria de una situación fáctica de paso prolongada en el tiempo, con los requisitos señalados el efecto, mediante el recurso a través de las Disposiciones Transitorias del citado Código civil a la prescripción inmemorial, reconocida en el derecho anterior (Siete Partidas). 
No obstante, transcurrido un tiempo, cambió la situación descrita, planteándose por un sector de la doctrina gallega, por primera vez y desde unas coordenadas que no eran las propiamente originales, como problema lo que antes no lo había sido.

En este sentido, tanto la circunstancia de que el recurso a la prescripción inmemorial se plantease en el ordenamiento jurídico común español no como una posibilidad general sino excepcional, a la que cabría acudir no ya directamente, sino por vía indirecta, conforme a las leyes anteriores al Código civil, así como el hecho de la posibilidad de utilización limitada con carácter general de la citada institución (prescripción) en relación a un determinado grupo de antiguos servicios de paso - "servidumbres de paso" que ya hubiesen sido adquiridas conforme a las leyes anteriores al Código civil y "servidumbres de paso" que vinieran ejercitándose con anterioridad al Código civil, que cumpliesen determinados requisitos y de las que no fuese posible recordar su origen ni tampoco un estado contrario; no reconocida para las "servidumbres de paso" que hubiesen empezado a ejercitarse después de 1889 (año de entrada en vigor del Código civil) — y, en especial, la consiguiente pérdida de idoneidad progresiva de la mencionada prescripción desde un punto de vista práctico, a consecuencia de la dificultad probatoria - acrecentada según se iba avanzando cada vez más en el tiempo- derivada de la exigencia establecida con cierto rigor por los tribunales de justicia en materia de prueba testifical en relación a los antiguos servicios de paso señalados — prueba que sería utilizable cuando no se dispusiese de otros medios probatorios reconocidos como aptos por el ordenamiento, lo cual sería bastante habitual, y que se concretaba en tener que recurrir con la finalidad de poder acreditar la existencia de la "servidumbre de paso" desde tiempo inmemorial a personas "idóneas", cuyo requisito de edad se iría ampliando cuanto más se fuese alejando la fecha de entrada en vigor del Código civil- provocaron la aludida reacción en un sector de la doctrina gallega posterior, principalmente situado en el ámbito de la abogacía, planteándose la cuestión como un problema, cada vez más dramático, que se podría sintetizar en la siguiente pregunta: ¿qué es lo que ocurrirá con tantas servidumbres como cruzan el agro gallego el día que sus poseedores no puedan demostrar su título, ni probar su ejercicio anterior a la vigencia del Código civil?

Sólo a partir de entonces y a consecuencia de la problemática aludida fue cuando, con mayor o menor intensidad y con mayor o menor fundamento, se empezó a criticar por un sector de la doctrina gallega la normativa recogida en el Código civil y también en algún caso a presentar de forma genérica y sin ningún apoyo concreto la inmemorialidad posesoria entendida como título de adquisición de servidumbres prediales de paso, como una de las costumbres más respetadas dentro del ámbito gallego, lo cual, según se indicó, como ha sido puesto de manifiesto tanto jurisprudencialmente como doctrinalmente, no se correspondía en absoluto con la realidad, que resultó notablemente distorsionada, introduciéndose en el ordenamiento jurídico civil gallego - más en concreto, por primera vez, en la LDCG de 1995, manteniéndose también en la vigente LDCG de 2006- la usucapión entre los modos de adquisición de las servidumbres prediales de paso. 
Por otro lado, en el caso de la denominada serventía -que aparece como una institución peculiar de Galicia (Rodríguez Montero, 2001: 63 y ss.; 2012: 34 nota 18), diferente de la servidumbre de paso, y que ha sido desarrollada por la jurisprudencia (Rodríguez Montero, 2001: 201 y ss.) e impropiamente utilizada en su momento como alternativa a los problemas planteados a consecuencia de la declaración jurisprudencial de irretroactividad en materia de adquisición por usucapión de las servidumbres de paso (Rebolledo Varela, 1999: 346) - , la regulación que de dicha figura ha realizado el legislador gallego — en los arts. 30 a 32 de la anterior y ya derogada LDCG de 1995, y 76 a 81 de la vigente LDCG de 2006-, a nuestro juicio no parece identificarse plenamente con la configuración y los caracteres que realmente presenta el tipo autóctono y originario que se da en la Comunidad gallega, que, a nuestro juicio, se concretaría específicamente en la denominada "servidumbre de agra".

Efectivamente, la lectura de las referencias que en la más antigua doctrina gallega se realizan en relación a los servicios de paso a través de las fincas permiten plantear la hipótesis de la existencia de unos determinados usos o práctica consuetudinaria, surgida en el seno de la comunidad a consecuencia de las necesidades derivadas del cultivo agrícola, o bien impuestas directamente por éste, que son sentidas por los miembros de esa comunidad al compartir una serie de intereses y problemas comunes, y que se presentan como posibles soluciones establecidas al margen del derecho con la finalidad de poder hacer frente a las dificultades que habitualmente venía planteando la situación minifundista, concretada en la excesiva distribución de la propiedad de la tierra en Galicia.

Precisamente tales antiguos servicios de paso - caracterizados en muchas ocasiones por su temporalidad y relación directa con la realización de tareas agrícolas-, que encontrarían su razón de ser más en la necesidad que en la utilidad, si no en su totalidad, sí, por lo menos, en su gran mayoría, significativamente, parecen referirse en una época antigua, con carácter exclusivo, a fincas situadas en unas superficies muy concretas, las denominadas "agras" o "vilares", en las que, a consecuencia de la situación de interdependencia e interclusión de las fincas en su interior, se establecerían una serie de relaciones de vecindad parcelaria. En nuestra opinión, sin embargo, nada tienen que ver con la configuración y caracterización originaria de las denominadas serventías, como se ha pretendido jurisprudencialmente y se ha sancionado legislativamente, determinados supuestos fácticos en los que los predios, evidentemente contiguos, no se encuentren enclavados en dichas distribuciones territoriales o geográficas (las referidas "agras"), exigiéndose únicamente en estos supuestos, como se señala en la ya clásica sentencia del Tribunal Superior de Justicia de Galicia, dictada con fecha de 24 de junio de 1997 (en la que, a nuestro juicio, se introdujo con carácter totalmente novedoso y sin fundamento histórico o apoyo antropológico alguno que permitiese justificar esa nueva figura de serventía referida al ámbito geográfico galaico, pasando a partir de entonces a formar parte del supuesto acervo jurídico-consuetudinario gallego, y que más adelante se procedería a "sacralizar" legislativamente, colocándola junto a la realmente originaria figura de serventía a que hemos hecho referencia anteriormente), el requisito 
de que se produzca una cesión, lógicamente voluntaria y consensuada, de una parte de terreno de cada "leira" o finca particular de los constituyentes, estableciéndose de esta forma - de mutuo acuerdo y mediante las correspondientes cesiones de parte del terreno realizadas al efecto- el camino serventío.

Además de los dos ejemplos expuestos -relativos a "peculiaridades jurídicas" gallegas inexistentes, o que, habiendo existido de forma efectiva, la regulación que se efectúa en la LDCG de las mismas aparece manipulada o alterada y no se corresponde con la configuración y características definitorias que realmente les corresponderían-, cabe citar también otros dos llamativos supuestos más, en los que, a nuestro juicio, se pueden apreciar las circunstancias indicadas: por una parte, la atinente a la que se presenta como institución tradicional gallega denominada "veciña" - a cuya regulación se dedican los arts. 52 a 55 de la vigente LDCG de 2006-; y, por otra, la relativa a la prescripción legal de indivisibilidad de la "casa" y sus anexos - considerada, como es sabido, como figura nuclear del Derecho civil de Galicia-, contenida en el art. 51 de la LDCG de 2006.

Por lo que se refiere a la "veciña", al presentársenos la misma como una institución de carácter consuetudinario, procedimos a preguntarnos en otro trabajo si la regulación que de la misma se realizaba en la vigente LDCG, se correspondía e identificaba con antiguas prácticas consuetudinarias gallegas, y, en su caso, en qué medida y con cuáles, acudiendo para ello a las diferentes fuentes de información proporcionadas por juristas, etnógrafos y antropólogos, poniéndolas a disposición de los lectores para que los mismos, al efectuar las comparaciones correspondientes con esos materiales, sacasen sin mayor dificultad sus propias conclusiones al respecto, pudiendo de esta forma comprobar las notables diferencias existentes entre la institución original y la que aparece recogida en la vigente LDCG (Rodríguez Montero, 2012: 283 y ss.). De la prescripción legal de la indivisibilidad de la "casa" y sus anexos nos ocupamos en otro artículo, analizando el que calificamos como paradójico proceso normativo operado en Galicia, tendente a establecer la llamativa indivisibilidad de la "casa patrucial" o "petrucial" gallega, que ha sido presentado como un dogma indiscutible por el legislador gallego en la LDCG al margen de cualquier justificación histórica o racional (Rodríguez Montero, 2012: 223 y ss.).A la vista de todo lo expuesto, en atención al proceso de elaboración, configuración y desarrollo del Derecho civil gallego, operado hasta llegar a la vigente LDCG del año 2006, se puede concluir que tanto la doctrina, como la Jurisprudencia (Rodríguez Montero, 2012: 35 y ss. y 43 y ss.), han desempeñado un papel fundamental en cuanto a los mismos, especialmente en situaciones de falta de claridad o de vacío normativo (Rodríguez Montero, 2012: 48 y nota 45).

Respecto al papel desarrollado por la doctrina, creímos que resultaba oportuno preguntarse, y así lo hicimos en otros escritos, entre otras, las siguientes cuestiones: ¿cuáles fueron los materiales jurídicos disponibles que se utilizaron, y cómo se utilizaron para confeccionar la LDCG de 1995 y la de 2006?; ¿qué criterios se siguieron para elegir dichos materiales?; ¿los criterios utilizados para realizar la confección de las mencionadas Leyes de 1995 y 2006, fueron los correctos?; ¿en qué medida en la LDCG de 1995, y en la de 2006, se recogen preceptos del —a veces tan criticado 
por un sector de la doctrina gallega - Código civil, o de la legislación civil de otras Comunidades Autónomas del Estado español —limitándose en ocasiones simplemente a reproducirlos, sin que encuentren sentido alguno en el cuerpo normativo gallego-, perdiendo el supuesto sentido autóctono que a dichas normas se atribuía y que, por lo menos, presuntamente, deberían de tener?.

A estas cuestiones se añadían otras incógnitas, no menos interesantes, que podían plantearse pensando en que las instituciones surgen para cubrir, en un contexto histórico muy concreto, unas necesidades también concretas y específicas que, lógicamente, pueden - y deben - cambiar con el transcurso del tiempo.

¿Cuáles fueron y cuáles son las viejas necesidades específicas que se plantearon en el pasado y cuáles son las nuevas que se plantean en el presente?; ¿qué es lo que ha cambiado y cómo ha cambiado?; ¿qué es lo que se ha mantenido y cómo se ha mantenido?. Estas eran y son algunas de las preguntas básicas que nos planteábamos y planteamos para proceder a determinar y establecer en qué se concretaba y en qué se concreta el antiguo y el actual Derecho civil de Galicia.

Precisamente para ello, hemos entendido que en un sistema jurídico-privado como el gallego, en el que a la costumbre se otorgó un papel fundamental, resultaba imprescindible recabar la colaboración, entre otros, de expertos en Antropología social, que, con sus conocimientos y a través de sus estudios de campo, pudiesen ayudar a clarificar las cuestiones planteadas, cuyo carácter interdisciplinar resultaba evidente (Rodríguez Montero, 2012: 54 nota 55).

\section{El importante papel otorgado a la costumbre en la LDCG de 1995. Los usos y costumbres notorios. La posible determinación jurisprudencial de la costumbre}

Por lo que se refiere a la posición que el legislador gallego otorgó a la costumbre en el sistema de fuentes del Derecho civil de Galicia, cabe señalar que en la LDCG de 1995, en opinión de un importante sector doctrinal, se la hacía prevalecer frente al Derecho parlamentario o legislado, según parecía deducirse de su articulado (Rodríguez Montero, 2010: 664 nota 10).

A consecuencia de las referencias que dicha Ley hacía a la costumbre - partiendo de la consideración de que al aludir a los usos o costumbres únicamente se estaría haciendo alusión a los usos y costumbres que no aparecían en el texto legal (costumbres territoriales, comarcales o locales), puesto que los recogidos en la Ley habían dejado de tener la consideración de uso o costumbre, para pasar a tener naturaleza legal-, se cuestionó, entre otros aspectos, por ejemplo, cuáles eran los usos y costumbres a los que se refería la Ley, a consecuencia de su formal desaparición, al pasar unos, según se decía, a normativa positiva legislada, y desaparecer otros en el año 1987, por convertirse la Compilación de 1963 en Derecho civil único de Galicia.

Respecto a la prueba de la costumbre, en el art. 2.1 de la LDCG de 1995 se indicaba que "los usos y costumbres notorios no requerirán prueba", especificándose a continuación el aludido concepto de notoriedad: "son notorios, además de los usos y costumbres compilados, los aplicados por el Tribunal Supremo, por el 
Tribunal Superior de Justicia de Galicia o por la antigua Audiencia Territorial de Galicia”.

La condición de notorio de un uso o costumbre presentaría, por consiguiente, una trascendental importancia en Derecho civil gallego, correspondiendo su determinación a los órganos jurisdiccionales.

Dicha notoriedad no tiene por qué ser absoluta y general, como se exige en el Derecho civil estatal, puesto que el gallego, como ha declarado el Tribunal Superior de Justicia de Galicia en su sentencia dictada con fecha de 12 de mayo de 2000, además de los usos y costumbres notorios relacionados con el texto legal, también se admite "que existan otros usos o costumbres notorios si existe constancia objetiva de su conocimiento generalizado". Todos aquellos usos y costumbres que no fuesen notorios, sensu contrario, deberán ser alegados ante el Tribunal y debidamente probados, aunque, no obstante lo indicado, se señalan otras dos posibilidades más en las cuales se sostiene que se produce una exención del cumplimiento del aludido requisito de su prueba, pudiendo, según se dice, ser aplicados por el juzgador de oficio: por un lado, cuando las partes intervinientes en el litigio se encontrasen conformes en su existencia y contenido, y sus normas no afectasen al orden público (en consonancia con lo prescrito en el art. 281.2 LEC 1/2000); y, por otro, cuando, sin ser alegados por las partes, el propio juzgador, teniendo conocimiento de los mismos - en cuyo caso, serían notorios para éste-, los considerase aplicables al supuesto en cuestión.

En cuanto a la determinación por parte de los órganos jurisdiccionales de los usos y costumbres que no fueron recogidos por el legislador gallego en la LDCG de 1995, al margen de las numerosas sentencias dictadas a consecuencia de cuestiones litigiosas planteadas con relación a las instituciones de marcado origen consuetudinario, que, por el contrario, sí aparecen recogidas en la Ley, así como de algunas otras resoluciones jurisdiccionales en las que dichos órganos procedieron a clarificar la correcta consideración de determinadas instituciones a las que pretendidamente se intentó enmarcar en el ámbito consuetudinario gallego, los Tribunales tuvieron la oportunidad de pronunciarse realizando diversas e importantes precisiones en torno a instituciones consuetudinarias, como los "montes abertales", "abiertos", "de varas", "de voces" o "de fabeo", el "resío" y la "venela", las "plantaciones de arbolado - en concreto, de eucalipto - en heredad contigua sin guardar distancias", la "gabia" o "gavia", la "costumbre de cara boa" y el "pé de rei" o "pé do rei".

La intervención jurisprudencial, que por evidentes razones de seguridad jurídica tuvo asimismo que ser tomada especialmente en consideración, induce a realizar dos observaciones, por lo que en particular se refiere al reconocimiento práctico - entendido como confirmación - de determinadas figuras o instituciones consuetudinarias, cuya posible existencia había resultado cuestionada por algún sector de la doctrina. Dicho reconocimiento jurisprudencial de tales figuras - no muy amplio en cuanto al número de sentencias dictadas, por lo que a algunas de esas figuras o instituciones se refiere-, por una parte, ha permitido rebatir las críticas realizadas a la LDCG de 1995 por un sector de la doctrina, considerándola como una norma que contenía instituciones de tipo fundamentalmente rural, desfasadas respecto al 
momento actual, y supuestamente extinguidas; por otra, induce a cuestionarse si tal reconocimiento jurisprudencial particularizado de dichas figuras - que, por lo demás, confirmaría su plena vigencia - realmente se identifica en todos los casos no sólo con la figura o institución concreta de que se trata, sino también con su espíritu y la función para la que teóricamente había surgido; o, más bien, la misma, en realidad, lo único que hace es mantener su denominación nominal, pero sin que, en el fondo, se corresponda con su auténtica esencia, contenido y función.

En definitiva, nos encontramos ante una importante y eficaz labor desarrollada por la Jurisprudencia, no exenta de dificultades, como, por ejemplo, hemos pretendido demostrar en un reciente trabajo en el que se analizan de forma crítica los problemas interpretativos surgidos en relación a la naturaleza jurídica de las "airas de mallar" en el ámbito rural gallego, tomando para ello como referencia tanto los distintos argumentos sostenidos por los Tribunales en orden a su consideración como comunidades de naturaleza germánica o romana, así como, por lo que aquí interesa, los iluminadores escritos antropológicos dedicados al análisis de la configuración y el funcionamiento de las mencionadas figuras tradicionales gallegas (Ramos Blanco, 2015).

\section{La posición de la costumbre en la vigente LDCG de 2006 y en el ordena- miento jurídico-civil de Galicia. El necesario recurso por parte de los juristas a los antropólogos como conclusión}

Por lo que se refiere a la vigente LDCG de 2006, cabe señalar que, frente a lo que ocurría en la anterior LDCG de 1995, en la que se adjudicaba a los "usos y costumbres propios" una "posición real de privilegio dentro de un aparente (y difícil) equilibrio con la ley no imperativa" (Lorenzo Merino, 2006: 21), en el Título preliminar de la vigente LDCG de 2006, en materia de fuentes se sitúa a la ley como primera en el orden de prelación de aquéllas, asumiendo la costumbre y los principios generales el carácter de supletorios respecto de la misma (art. 1), agotando de esta forma, según se ha dicho, la "pretensión historicista de considerar la costumbre como primer título competencial sobre el que desarrollar la actividad legislativa". No obstante lo indicado, también se resalta que la propia costumbre sigue manteniendo actualmente el "beneficio de exención de prueba en caso de ser notoria" (art. 2.1 LDCG de 2006, cuya redacción coincide plenamente con la del antiguo artículo 2.1 de la LDCG de 1995) (Lorenzo Merino, 2006: 29).

Todo lo hasta aquí expuesto creemos que avala suficientemente el planteamiento efectuado en el presente artículo en relación a la necesidad por parte de los juristas de recurrir a la Antropología al tratar aspectos relativos tanto al pasado como al presente y al futuro de la experiencia jurídica gallega, conclusión ésta que resulta, si cabe, todavía más reforzada cuando atendemos a la previsión revisora establecida en la Disposición adicional primera de la LDCG de 2006 - que, en esencia, coincide con la segunda de las también adicionales de la anterior LDCG de 1995- relativa al examen de las instituciones del Derecho gallego a conservar, modificar o desarrollar, con la finalidad de adecuar su situación a las actuales circunstancias sociales de la Comunidad, dando cumplida solución a la problemática jurídica que se pudiese plantear. 


\section{Referencias bibliográficas}

LORENZO MERINO, Fernando.

2006 Ley de Derecho civil de Galicia $2^{\mathrm{a}}$ ed. (Prólogo). Madrid: Ed. Tecnos (Grupo Anaya S.A.).

RAMOS BLANCO, José Luis.

2015 "Notas sobre la consideración jurídica de las "eiras de mallar" en Galicia" (en prensa), admitido para publicación: en el Anuario da Facultade de Dereito da Universidade da Coruña, 19; y en los Estudios Homenaje al Prof. Dr. D. Luis Rodríguez Ennes. Vigo: Universidade de Vigo (en prensa).

REBOLLEDO VARELA, Ángel Luis.

1999 Los derechos reales en la Ley 4/1995 de 24 de mayo de Derecho civil de Galicia. (Montes vecinales en mano común, aguas, servidumbre de paso y serventía). Pontevedra: Ed. Revista Xurídica Galega.

RODRÍGUEZ MONTERO, Ramón P.

2001 Servidumbres y serventías. Estudios sobre su regulación jurídica y desarrollo jurisprudencial. A Coruña: Netbiblo.

2005 "La costumbre y el Derecho consuetudinario gallego". Revista Jurídica del Notariado, 54 (abril-junio): 187-223.

2010 "Costumbre, Derecho consuetudinario y Ley en el ámbito jurídico-civil gallego", en J. Marcos Arévalo, S. Rodríguez Becerra y E. Luque Baena (Eds.), Nos-Otros: Miradas antropológicas sobre la diversidad, vol. I. Mérida: Departamento de publicaciones. Asamblea de Extremadura: 657-671.

2012 Galicia y su Derecho privado. Líneas históricas de su formación, desarrollo y contenido. Santiago de Compostela: Andavira Editora S.L. 